\title{
Comunicação
}

[Communication]

\section{Efeitos genéticos e ambientais sobre a idade à primeira concepção de fêmeas suínas}

\section{[Estimates of genetic and environmental effects on age at first conception of gilts]}

\author{
A. Cavalcante Neto ${ }^{1}$, J.F. Lui $^{1}$, J.L.R. Sarmento ${ }^{2}$, M.N. Ribeiro ${ }^{3}$, J.M.C. Monteiro ${ }^{1}$, \\ C. Fonseca ${ }^{4}$, H. Tonhati ${ }^{1}$ \\ ${ }^{1}$ Faculdade de Ciências Agrárias e Veterinárias - UNESP \\ Via de Acesso Prof. Paulo Donato Castellane, s/n \\ 14884-900 - Jaboticabal, SP \\ ${ }^{2}$ Universidade Federal do Piauí - Campus de Bom Jesus, PI \\ ${ }^{3}$ Universidade Federal Rural de Pernambuco - Recife, PE \\ ${ }^{4}$ Departamento de Biologia/CESAM - Universidade de Aveiro - Aveiro, Portugal
}

De acordo com Freitas (1998), a diminuição da idade à puberdade significa menor idade no acasalamento e no primeiro parto, reduzindo a idade de entrada das fêmeas no plantel, o que representa, do ponto de vista econômico, menor custo de produção de leitões. Esse autor ressaltou, ainda, que a herdabilidade estimada dessa característica é $0,30 \%$ e que há variação aditiva e efeitos pleiotrópicos abundantes para mudanças na idade à puberdade.

As diferenças observadas entre os indivíduos são resultado da influência de fatores genéticos e ambientais. $\mathrm{O}$ componente genético é estritamente uma função dos genes do indivíduo. Embora a seleção de animais, em um programa de melhoramento genético, seja realizada pelo componente genético, ênfase deve ser dada ao componente ambiental, pois os efeitos ambientais, apesar de não serem transmitidos através das gerações, devem ser considerados para a determinação precisa do valor genético do indivíduo (Pita e Albuquerque, 2001). Assim, este trabalho objetiva avaliar os fatores genéticos e ambientais que afetam a idade à primeira concepção (IPC) de leitoas no Sudeste do Brasil.

Utilizaram-se 466 observações para IPC de animais Dalland (C-40), pertencentes à granja São José - Irmãos Canalli (rebanho 1), situada no município de Monte Alto-SP, e à Suinocultura São José (rebanho 2), situada no município de Cabo Verde - MG.

Os animais estavam todos em instalações convencionais de alvenaria de tijolos, revestidas de cimento e piso impermeável, com piquetes nas unidades destinadas à reprodução. A ração fornecida era do tipo comercial, atendendo às exigências nutricionais de todas as fases da criação.

Para análises dos dados, agruparam-se as estações de nascimento em quatro trimestres: 1 janeiro a março; 2 - abril a junho; 3 - julho a setembro; e 4 - outubro a dezembro. Com o intuito de tornar os dados mais consistentes, foram feitas algumas restrições, considerando, para análise, apenas informações de reprodutores com, no mínimo, três filhas. Definiu-se, também, que os grupos contemporâneos deveriam ter, no mínimo, quatro animais. Feitas as restrições, restaram 466 registros de idade à primeira concepção de porcas filhas de 15 cachaços e 120 matrizes.

As análises dos efeitos ambientais foram realizadas pelo procedimento GLM dos SAS (User's..., 1999), considerando-se a opção RANDOM, que trata o efeito de reprodutor como 
aleatório, utilizando-se o seguinte modelo estatístico:

$\mathrm{Y}_{\mathrm{ijklmn}}=\mu+\mathrm{C}_{\mathrm{i}}+\mathrm{M}_{\mathrm{j}}+\mathrm{A}_{\mathrm{k}}+\mathrm{E}_{1}+\mathrm{R}_{\mathrm{m}}+\mathrm{e}_{\mathrm{ijklmn},} \mathrm{em}$ que:

$\mathrm{Y}_{\mathrm{ijklm}}=$ observação da idade à primeira concepção; $\mu=$ média geral; $\mathrm{C}_{\mathrm{i}}=$ efeito aleatório do cachaço pai da leitoa dentro de rebanho; $\mathrm{M}_{\mathrm{j}}=$ efeito aleatório da matriz mãe da leitoa dentro de rebanho; $A_{k}=$ efeito fixo do ano de nascimento (2000 a 2004); $E_{1}=$ efeito fixo da estação de nascimento (1, 2, 3 e 4); $\mathrm{R}_{\mathrm{m}}=$ efeito fixo do rebanho de nascimento ( 1 e 2 ); $\mathrm{e}_{\mathrm{ijklm}}=$ erro aleatório associado a cada observação, $\operatorname{com} \mu=0$ e variância $=\delta^{2}$.

No modelo para análise ambiental, foram testados os efeitos de todas as possíveis interações entre os efeitos fixos e, como não apresentaram significância estatística, foram excluídos das análises.

As estimativas dos componentes de variância e parâmetro genético foram obtidas, utilizando-se o aplicativo MTDFREML, descrito por Boldman et al. (1995), que utiliza a metodologia da máxima verossimilhança restrita livre de derivadas. $\mathrm{O}$ critério de convergência utilizado foi a variância dos valores do simplex inferior a $10^{-9}$. Após a convergência, o programa era reiniciado, usando-se as estimativas obtidas anteriormente como valores iniciais. Esse procedimento foi repetido até que a diferença entre as estimativas das duas últimas convergências não diferissem.

A análise foi realizada sob modelo animal, que incluía como efeito fixo, grupo de contemporâneos - formado pelo ano e estação de nascimento e rebanho - e, como aleatório, os efeitos genético aditivo, comum de leitegada e o erro.

A média estimada da idade à primeira concepção foi de 241,12 $\pm 25,9$ dias, com coeficiente de variação de $8,5 \%$. Essa média, embora seja de matriz Dalland, está condizente com o que sugere o Manual Naima ${ }^{1}$, o qual afirma que as matrizes Naima devem, preferencialmente, ser cobertas aos 240 dias de idade, com, aproximadamente, $140 \mathrm{~kg}$ de peso e $14 \mathrm{~mm}$ de

${ }^{1}$ Pen Ar Lan

http://WWW.penarlan.com.br/download/ManualNaima2007. toucinho dorsal (no P2 - 6,5 cm da linha dorsolombar).

As leitoas representam uma grande proporção do plantel de uma granja. Além disso, o momento da primeira cobrição pode ter influência sobre o desempenho subseqüente dos animais e, conseqüentemente, sobre a eficiência reprodutiva do rebanho. Todavia a definição da idade mais adequada para o primeiro serviço ainda gera controvérsias. $\mathrm{O}$ aproveitamento do primeiro serviço de leitoas em idades mais novas levaria a um menor acúmulo de dias não-produtivos, com redução nos custos de produção (Schukken, 1994; Culbertson e Mabry, 1995; Lucia Jr. et al., 2000).

Existe muita dúvida, por parte dos produtores, para definir o melhor cio de cobrição, havendo diferentes orientações de técnicos e fornecedores de material genético (Amaral, 2003). Essa definição deve levar em consideração alguns aspectos, como idade, desenvolvimento e reserva corporal das leitoas (Foxcroft, 1998).

Lúcia Jr. et al. (2003) afirmaram que a idade ao primeiro serviço abaixo de 200 dias está associada ao maior risco de repetição de cios em fêmeas nulíparas, mas não há efeito sobre o total de leitões nascidos vivos e sobre o subseqüente intervalo desmame-primeiro serviço. A decisão quanto à idade ao primeiro serviço deve considerar as particularidades de cada granja, em função das especificações de diferentes bases genéticas.

Os efeitos de ano $(\mathrm{P}<0,01)$ e estação $(\mathrm{P}<0,01)$ sobre a IPC foram significativos. Sabe-se que esses efeitos dependem do manejo, da alimentação e qualidade dos ingredientes e das condições climáticas. A alimentação é, certamente, o efeito mais sensível e mais influenciado pelo homem. Para Irgang (1990), a menor ou maior idade à puberdade depende da estação e do ano de nascimento das leitoas, de sua movimentação, envolvendo a troca de baias, do regime alimentar, do número de leitoas por grupo na fase de pré-puberdade e da presença e estímulo do macho.

Neste trabalho, o efeito de rebanho $(\mathrm{P}<0,01)$, que reflete um conjunto de práticas de manejo utilizadas em cada propriedade, constituiu importante fonte de variação da IPC. Vários 
autores afirmaram que as diferenças entre os rebanhos é um fator que pode afetar significativamente as características reprodutivas de fêmeas suínas (Strang, 1970; Fedalto, 1979; Alves, 1986).

$\mathrm{O}$ efeito do cachaço $(\mathrm{P}=0,34)$ não foi importante para a IPC, mas o efeito da porca (mãe da leitoa) foi importante fonte de variação da característica $(\mathrm{P}<0,01)$.

A estimativa de herdabilidade para a idade à primeira concepção foi de $0,44 \pm 0,14$, considerada de alta magnitude, indicando que a característica apresentaria ganho genético como resposta à seleção. Esse valor encontra-se próximo ao de Irgang (1985), que encontrou estimativa de herdabilidade de 0,47 .

A estimativa do efeito comum de leitegada foi de $0,20 \pm 0,07$, demonstrando a importância de se incluir, nos modelos de análises genéticas, esse efeito, uma vez que foi responsável por $20 \%$ da variação fenotípica total. Nesse sentido, Mrode
(1996) ressaltou que a inclusão do efeito ambiental comum no modelo aumenta a acurácia na predição do valor genético dos animais. Torres Filho et al. (2005) relataram que a estimativa do efeito comum de leitegada, para idade da porca ao primeiro parto, destaca a importância de sua inclusão no modelo de avaliação para essa característica, uma vez que foi responsável por $11 \%$ da variação fenotípica total.

Conclui-se que, para uma acurada comparação genética, deve-se levar em consideração o ano e a estação de nascimento, assim como o efeito de rebanho, devendo, para isso, juntar os animais em grupos de contemporâneos. $\mathrm{O}$ valor estimado de herdabilidade para idade da porca à primeira concepção indica que essa característica apresentaria ganho genético como resposta à seleção massal.

Palavras-chave: suíno, fatores não genéticos, parâmetro genético, puberdade

\section{ABSTRACT}

The genetic and environmental factors that affect age at first conception (AFC) of gilts were evaluated, using 466 observations of Dalland animals (C-40). The software program MTDFREML was used to assess the genetic parameters on an animal model that included as fixed effect, contemporary group and, as random effects, the additive genetic, the common litter and the error. Mean value of AFC was $241.12 \pm 25.9$ days, with $C V$ of $8.5 \%$. Variance analysis showed that year $(P<0.01)$, season $(P<0.01)$ and herd effects $(P<0.01)$ were important sources of variation of $A F C$. The throat effect $(P=0.34)$ was not important for the AFC, but the mother of the gilts $(P<0.01)$ was an important source of variation. The heritability estimate was $0.44 \pm 0.14$ that this trait would yield genetic gain as a response to the selection.

Keywords: swine, non genetic effects, genetic parameter, puberty

\section{REFERÊNCIAS BIBLIOGRÁFICAS}

ALVES, R.G.O. Estudo genético de características reprodutivas em suínos e avaliação de curvas de crescimento em cruzamentos dialélicos. 1986. 124f. Tese (Doutorado) - Universidade Federal de Viçosa, Viçosa, MG.

AMARAL, A.L.; MORÉS, N.; BARIONI JÚNIOR, W. Avaliação do manejo adotado em leitoas de reposição em duas granjas comerciais sobre o desempenho reprodutivo até o terceiro parto. In: CONGRESSO BRASILEIRO DE VETERINÁRIOS ESPECIALISTAS EM
SUÍNOS, 11., 2003, Goiânia. Anais... Goiânia: ABRAVES, 2003, p.173-174.

BOLDMAN, K.G.; KRIESE, L.A.; Van VLECK, D.L. et al. A manual for use of $M T D F R E M L$. A set of programs to obtain estimates of variances and covariances [DRAFT] Lincoln: USDA/ARS, 1995. 120p.

CULBERTSON, M.S.; MABRY, J.W. Effect of age at first service on first parity and lifetime sow performance. J. Anim. Sci., v.73, suppl.1, p.21, 1995 .

FEDALTO, L.M. Fontes de variação de tamanho e peso de leitegada, do nascimento aos 21 dias de idade, nas raças Duroc, Landrace e 
Large White. 1979. 83f. Dissertação (Mestrado) - Universidade Federal de Viçosa, Viçosa, MG.

FOXCROFT, G.; AHERNE, F.; KIRKWOOD, R. Managing the replacement gilt. In: SEMINÁRIO INTERNACIONAL DE SUINOCULTURA, 3., 1998, São Paulo, Anais... Concórdia: Embrapa Suínos e Aves, 1998. p.4359.

FREITAS, R.T.F. Situação atual e perspectiva do melhoramento de suínos. In: CONGRESSO NACIONAL DOS ESTUDANTES DE ZOOTECNIA, 1998, Viçosa. Anais ... Viçosa: UFV, 1998. p.461-471.

IRGANG, R. Estimativas de herdabilidade para características que compõem a produtividade anual de leitões por porca. Concórdia: Embrapa Suínos e Aves, 1985. 4p. (Comunicado Técnico, 81).

IRGANG, R.; SCHEID, I.R.; FÁVERO, J.A. Aumento do peso e redução da idade à puberdade de leitoas através dos cruzamentos. Concórdia: Embrapa Suínos e Aves, 1990. 3p. (Comunicado Técnico, 151).

LUCIA, T.; DIAL, G.D.; MARSH, W.E. Reproductive and financial efficiency during lifetime of female swine. J. Am. Vet. Med. Assoc., v.216, p.1802-1809, 2000.

LUCIA Jr., T.; BIANCHI, I.; RECH, H. et al. Parâmetros de desempenho reprodutivo de fêmeas nulíparas e primíparas em função da idade ao primeiro serviço. In: CONGRESSO BRASILEIRO DE VETERINÁRIOS ESPECIALISTAS EM SUÍNOS, 11., 2003, Goiânia, Anais... Goiânia: ABRAVES, 2003. p.175-176.

MRODE, R.A. Linear models for the prediction of animal breding values. Guildford: CAB International, 1996. 187p.

PITA, F.V.C.; ALBUQUERQUE, L.G. Efeitos da utilização de diferentes covariáveis na avaliação do ganho de peso médio diário em suínos. Rev. Bras. Zootec., v.30, p.736-743, 2001.

SCHUKKEN, Y.H.; BUURMAN, J.; HUIRNE, R.B.M. et al. Evaluation of optimal age at first conception in gilts from data collected in commercial swine herds. J. Anim. Sci., v.72, p.1387-1392. 1994.

STRANG, G.S. Litter productivity in Large White pigs. I. The relative importance of some sources of variation. Anim. Prod., v.12, p.225233, 1970.

TORRES FILHO, R.A.; TORRES, R.A.; LOPES, P.S. et al. Estimativas de parâmetros genéticos para características reprodutivas de suínos. Arq. Bras. Med. Vet. Zootec., v.57, p.684-689, 2005.

USER'S guide: statistics. Version 6. 4.ed. Cary: SAS Institute, 1999. 1686p. 